\title{
The microstructure and wear behaviour of sintered Astaloy 85Mo
}

\author{
K. E. Öksüz ${ }^{1}$, T. Gün ${ }^{2} \&$ M. Şimşirir \\ ${ }^{1}$ Metallurgical and Materials Engineering Department, \\ Cumhuriyet University, Turkey \\ ${ }^{2}$ ESTAS Camshaft \& Chilled Cast, Turkey
}

\begin{abstract}
Powder metallurgy enables cost effective production of powder metallurgy (PM) parts with complex geometries in automotive applications. PM materials are also extensively used for the production of components subjected to working conditions giving rise to sliding, rolling or abrasive wear, such as gears or cams. In this experimental study, Fe based pre-alloyed Astaloy 85Mo powder was used in the production of camshaft spur gear. The gas carburizing is carried out at $925^{\circ} \mathrm{C}$ for 3 hours. The camshaft spur gears were waited at $850^{\circ} \mathrm{C}$ for 1 hour to reach the required carbon concentration. Oil hardening is carried out at $82^{\circ} \mathrm{C}$, soaking time is $30 \mathrm{~min}$. The effect of gas carburizing on the microstructure, density, hardness and wear properties of Astaloy $85 \mathrm{Mo}+0.5 \%$ graphite was investigated. Furthermore, the microstructure characterization and worn surfaces of camshaft spur gear were examined using a high magnification optical microscope.
\end{abstract}

Keywords: powder metallurgy, Astoloy 85Mo, gas carburizing, wear.

\section{Introduction}

Demands on gear materials are continuously increasing. This is mainly because of developments in the automotive industry towards high performance vehicles with low fuel consumption and low environmental impact. A good example can be to look on car gear transmissions as very demanding ones. In the period from World War II to the present, their gear module decreased from between 4 and $5 \mathrm{~mm}$ down to between 2 to $3 \mathrm{~mm}$, while effective torque transmitted increased nearly twice [1]. Powder metallurgy enables cost effective production of gears 
and parts with complex geometries. Besides that there are some advantages of $\mathrm{P} / \mathrm{M}$ technique such as near net shape, green technique and almost no waste material. Surface quality is very important in production of a gear by $\mathrm{P} / \mathrm{M}$ technique. In order to improve mechanical properties and surface quality of a gear, some methods are applied such as gear rolling for surface densification, heat treatment for hardness of $\mathrm{P} / \mathrm{M}$ part and case hardening for improving surface hardness. Gear rolling is a well-known technology for improving the shape, surface densification and surface finish of steel gears [2-5]. Gas carburizing is a surface hardening method in which the surface of the components is saturated with carbon in a gaseous atmosphere containing carbon to accomplish this, the components are first heated in a neutral atmosphere to a predetermined temperature in the range of 870 to $940^{\circ} \mathrm{C}$. The furnace is flooded with a suitable gas such as propane, butane or methane. Finally, the components are held at this temperature to allow for the diffusion of carbon into the case. After the carburizing treatment is completed, the components are quenched to obtain the required hardness, wear resistance and fatigue resistance on the surface, supported by a tougher core [6]. The mechanical behavior of sintered steels have been studied mainly by tensile and impact testing procedures [7]. However, the demand for components displaying an adequate resistance under heavy stress conditions, e.g. engine parts and transmission gears, has promoted considerable research efforts on PM components suitable to work under dynamic conditions. PM materials are also extensively used for the production of components subjected to working conditions giving rise to sliding, rolling or abrasive wear, as well as gears or cams. Therefore, a complete understanding of their tribological behavior is important. Several results on the dry sliding behavior of sintered ferrous alloys can be found in the literature [8-13]. In this paper, effect of gas carburization on microstructure and wear properties of hot pressed Astaloy $85 \mathrm{Mo}$ was investigated. Wear and micro hardness test were conducted and the mechanical properties were evaluated on the basis of microstructure.

\section{Experimental procedure}

\subsection{Materials and method}

The $\mathrm{P} / \mathrm{M}$ steels were produced in an industrial plant using pre-alloyed Astoloy 85Mo (Höganäs) powders. A planetary gear with the gear data given in Table 1 was used in this study. Fig. 1 shows the camshaft spur gear configuration and Astaloy $85 \mathrm{Mo}$ with the compositions shown in Table 2 were used as base materials for the gears. PM camshaft spur gear has been manufactured by compaction of cylindrical blanks followed by sintering at $1130^{\circ} \mathrm{C}$ for $30 \mathrm{~min}$ in a mixture of $90 \% \mathrm{~N}_{2}$ and $10 \% \mathrm{H}_{2}$ gas atmosphere by Sintek Powder Metallurgy Company. Carbon was added as ultra-fine natural graphite (UF4 graphite). Lubricant (Intralube ${ }^{\circledR} \mathrm{E}$ ) in proportion to $0.8 \mathrm{wt} \%$ was added to the powdergraphite mixtures. 
Table 1: Gear geometry.

\begin{tabular}{|l|l|l|}
\hline & & \\
\hline Number of teeth & $\mathrm{Z}$ & 42 \\
\hline Normal module & $\mathrm{mn}$ & 1.25 \\
\hline Major diameter & $\mathrm{De}$ & $\emptyset 55.80 \pm 0.05$ \\
\hline Pitch diameter & $\mathrm{Do}$ & $\emptyset 53.28$ \\
\hline Minor diameter & $\mathrm{Di}$ & $\emptyset 48.78+0$ \\
& & \multicolumn{1}{|c|}{-0.2} \\
\hline Depth of tooth type & $\mathrm{hk}$ & 1.26 \\
\hline Tooth thickness & $\mathrm{Sc}$ & $1.66 \pm 0.02$ \\
\hline Grip angle & $\alpha \mathrm{o}$ & $17^{\circ} 30^{\prime}$ \\
\hline Diameter with pin with two pins & & $\emptyset 57.72 \pm 0.05$ \\
\hline Max shimmy & & 0.03 \\
\hline Pin diameter & $\mathrm{P} 18$ & $\varnothing 2.77$ \\
\hline
\end{tabular}

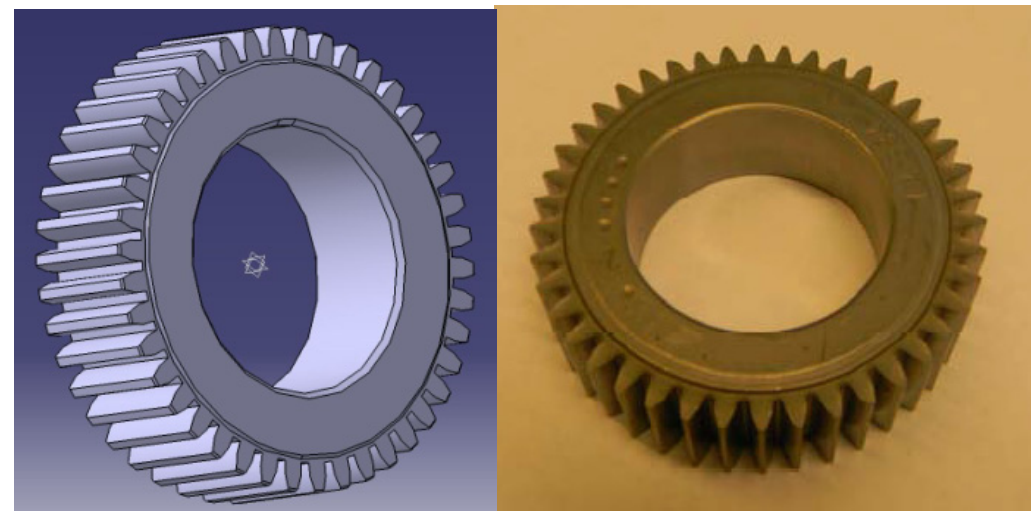

Figure 1: Configuration of the Astaloy $85 \mathrm{Mo}+0.5 \% \mathrm{C}$ camshaft spur gear.

Table 2: Chemical composition of base powders (wt. \%).

\begin{tabular}{|l|l|l|l|l|l|l|}
\hline Gear & Material & $\begin{array}{l}\mathrm{Cu} \\
(\%)\end{array}$ & $\begin{array}{l}\mathrm{Ni} \\
(\%)\end{array}$ & $\begin{array}{l}\text { Mo } \\
(\%)\end{array}$ & $\begin{array}{l}\mathrm{C} \\
(\%)\end{array}$ & $\begin{array}{l}\mathrm{S} \\
(\%)\end{array}$ \\
\hline $\begin{array}{l}\text { Camshaft } \\
\text { spur gear }\end{array}$ & $\begin{array}{l}\text { Astoloy } \\
85 \mathrm{Mo}\end{array}$ & 0.04 & 0.04 & 0.85 & 0.48 & 0.005 \\
\hline
\end{tabular}

\subsection{Heat treatment}

The gas carburizing was performed at $925^{\circ} \mathrm{C}$ for 3 hours. The camshaft spur gears were waited at $850^{\circ} \mathrm{C}$ for 1 hour to reach the $\% \mathrm{C}$ concentration 0.72 . Oil hardening is carried out at $82^{\circ} \mathrm{C}$, soaking time is $30 \mathrm{~min}$. 


\subsection{Mechanical tests}

Vickers micro hardness values were measured under a load of $1 \mathrm{~kg}-\mathrm{f}$ for each sample and microstructure of the gear was examined using high magnification optical microscope. For wear test, a pin-on-disc type apparatus was employed to evaluate the wear characteristics of samples. AISI 5190 steel disc having $65 \mathrm{HRc}$ with $12 \mathrm{~mm}$ thick, and $160 \mathrm{~mm}$ diameter was used to serve as the adhesive medium. The pin specimens made from the samples were machined to approximately $5 \mathrm{~mm}$ in length. The pin was then mounted in a steel holder in the wear machine so that it was held firmly perpendicular to that of the flat surface of rotating counter disc. The samples were loaded against the abrasive medium with the help of a cantilever mechanism. Wear test was performed under varied loads such as; 20, 40 and $60 \mathrm{~N}$ and at a constant speed of $1 \mathrm{~m} / \mathrm{s}$ and a constant sliding distance of $60 \mathrm{~m}$ with 80 mesh $\mathrm{SiC}$ paper for each sample. After the test, the wear pin was cleaned in acetone prior to and after the wear tests, and then dried after being weighed on a micro-balance with $0.1 \mathrm{mg}$ sensitivity. Wear tests were carried out three times for three samples with and without gas carburized samples. Average of amount of weight loss was calculated and presented. Meanwhile confirmation tests were carried out at $60 \mathrm{~N}$ and at a constant speed of $1 \mathrm{~m} / \mathrm{s}$ and a constant sliding distance of $150 \mathrm{~m}$ with 80 mesh $\mathrm{SiC}$ paper for each spur gear. After the confirmation test worn surface micrographs were taken using high magnification optical microscope.

\section{Results and discussion}

\subsection{Microstructural analyses}

Microstructure of the cam shaft spur gear was examined using high magnification optical microscope. After grinding and polishing, the samples were etched with solution of $\% 2$ Nital. Fig. 2 shows the microstructural aspects of the Astaloy $85 \mathrm{Mo}+0.5 \% \mathrm{C}$ and gas-carburized Astaloy $85 \mathrm{Mo}+0.5 \% \mathrm{C}$ samples.

Figure 2(a) shows the microstructure of the Astaloy $85 \mathrm{Mo}+0.5 \% \mathrm{C}$ at sintering at $1130{ }^{\circ} \mathrm{C}$ for $30 \mathrm{~min}$ in a mixture of $90 \% \mathrm{~N}_{2}$ and $10 \% \mathrm{H}_{2}$ gas atmosphere. It can be seen that the microstructure of sintered sample is ferritic. Figure 2(b) shows the microstructure in the gas-carburized Astaloy $85 \mathrm{Mo}+0.5 \% \mathrm{C}$ spur gears. The microstructure is plate martensite that has high carbon content at the surface and in the core which is lath martensite with low carbon content.

\subsection{Hardness and wear resistance}

Micro-hardness was measured under 40x objective and an applied load of $1 \mathrm{~kg}-\mathrm{f}$ using Vickers micro hardness tester. Five readings were taken and the hardness value has been reported in Figure 3. The blank density was $6.91-6.95 \mathrm{~g} / \mathrm{cm}^{3}$ range for the camshaft spur gear before the gas carburizing process and the 

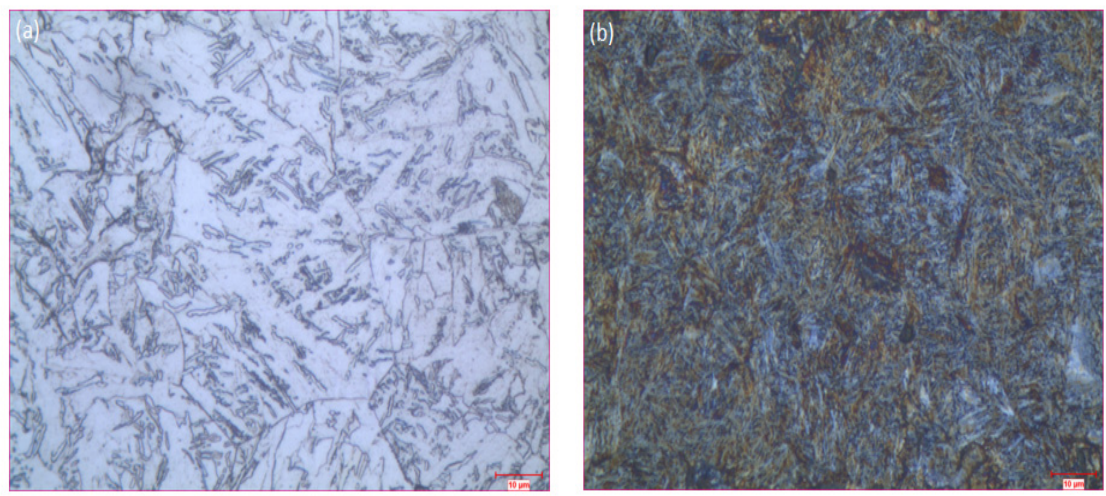

Figure 2: Microstructure photographs of (a) Astaloy $85 \mathrm{Mo}+0.5 \% \mathrm{C}$ and (b) gas-carburized Astaloy $85 \mathrm{Mo}+0.5 \% \mathrm{C}$ materials.

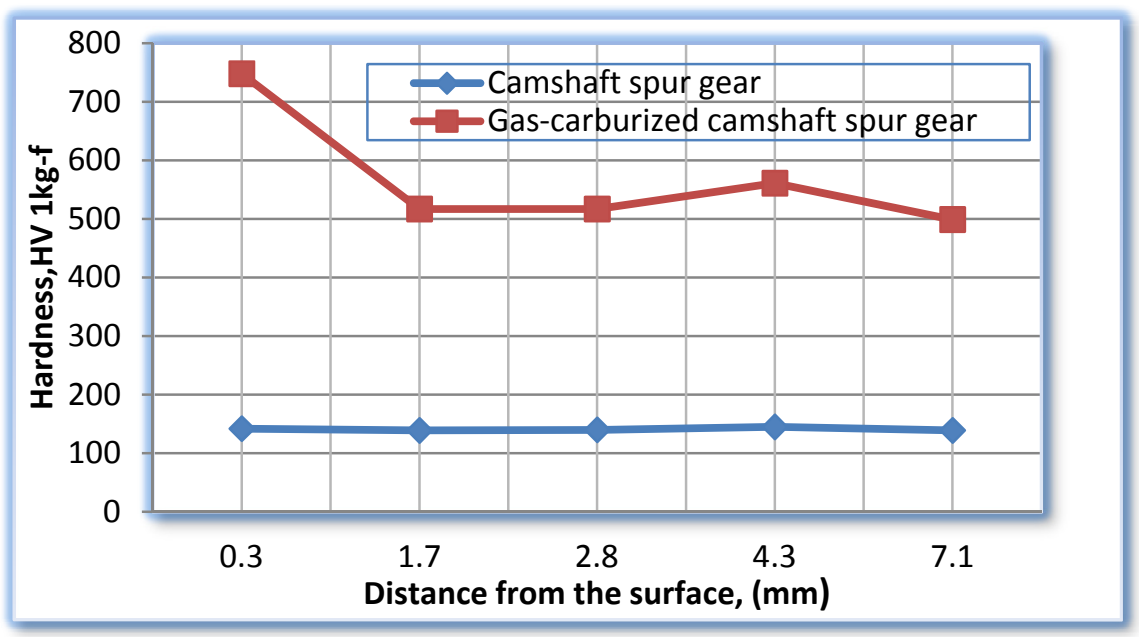

Figure 3: Micro-Hardness's for the Astaloy $85 \mathrm{Mo}+0.5 \% \mathrm{C}$ and gas carburized Astaloy $85 \mathrm{Mo}+0.5 \% \mathrm{C}$ spur gear.

surface micro hardness values is $142-139 \mathrm{HV}$ in the range of $0.3-7.1 \mathrm{~mm}$. After the gas carburizing process the blank density is $7.036-7.05 \mathrm{~g} / \mathrm{cm}^{3}$ range for the camshaft spur gear and the surface hardness is $748-499 \mathrm{HV}$ in the range of $0.3-$ $7.1 \mathrm{~mm}$.

Fig. 4 shows the results of wear resistance for the the Astaloy $85 \mathrm{Mo}+0.5 \% \mathrm{C}$ and gas carburized Astaloy $85 \mathrm{Mo}+0.5 \% \mathrm{C}$ spur gear. The wear rate increased more or less linearly with increasing load for all tested samples. The wear rate was slightly higher for the Astaloy $85 \mathrm{Mo}+0.5 \% \mathrm{C}$ spur gear due to decreased hardness and its microstructure. 


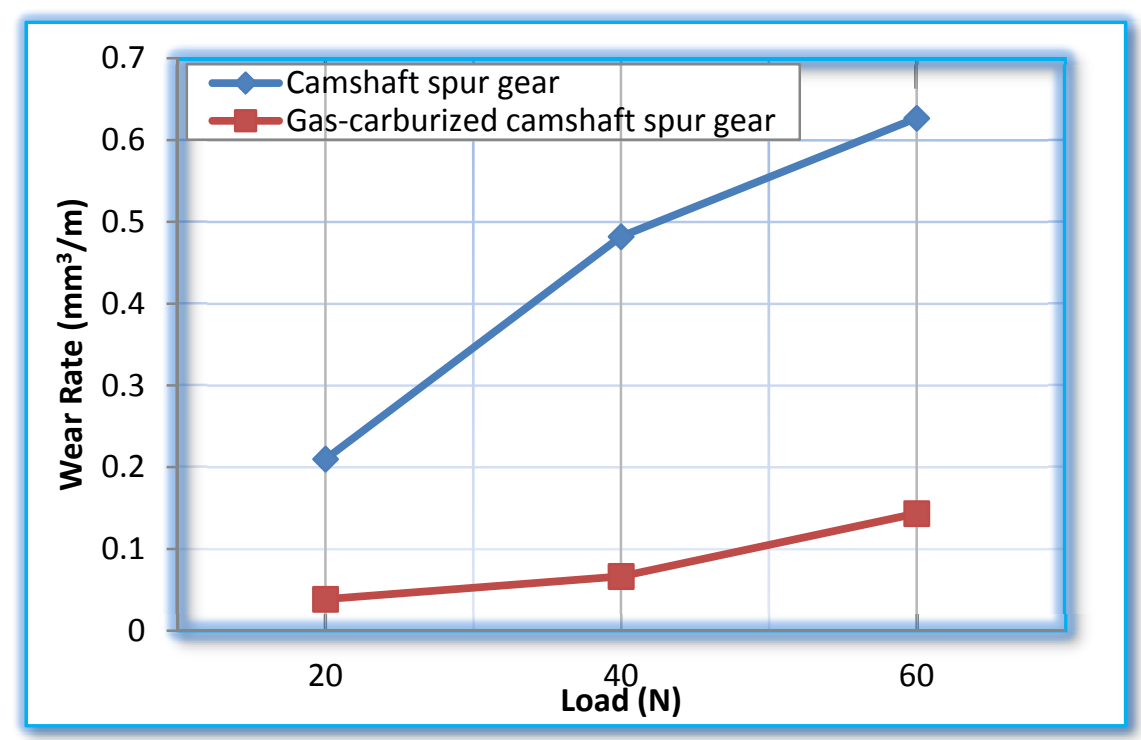

Figure 4: Results of wear resistance for the spur gears.

The worn surfaces, after tests carried out at $60 \mathrm{~N}$, with $\mathrm{SiC}$ paper (abrasive size $=201 \mu \mathrm{m}$ ) were characterized by the presence of fine and coarse grooves parallel to the sliding direction. Worn surfaces of the Astaloy $85 \mathrm{Mo}+0.5 \% \mathrm{C}$ camshaft spur gear showing cracking of flakes along the wear track (marked arrow), diversion of wear grooves (Fig. 5(a)). Gas carburized Astaloy $85 \mathrm{Mo}+0.5 \% \mathrm{C}$ camshaft spur gear showing abrasive traces, wear debris (marked arrow), material removal without delamination (Fig. 5(b)). Figure 5 shows the worn surfaces of the Astaloy $85 \mathrm{Mo}+0.5 \% \mathrm{C}$ and gas carburized Astaloy $85 \mathrm{Mo}+0.5 \% \mathrm{C}$ samples.
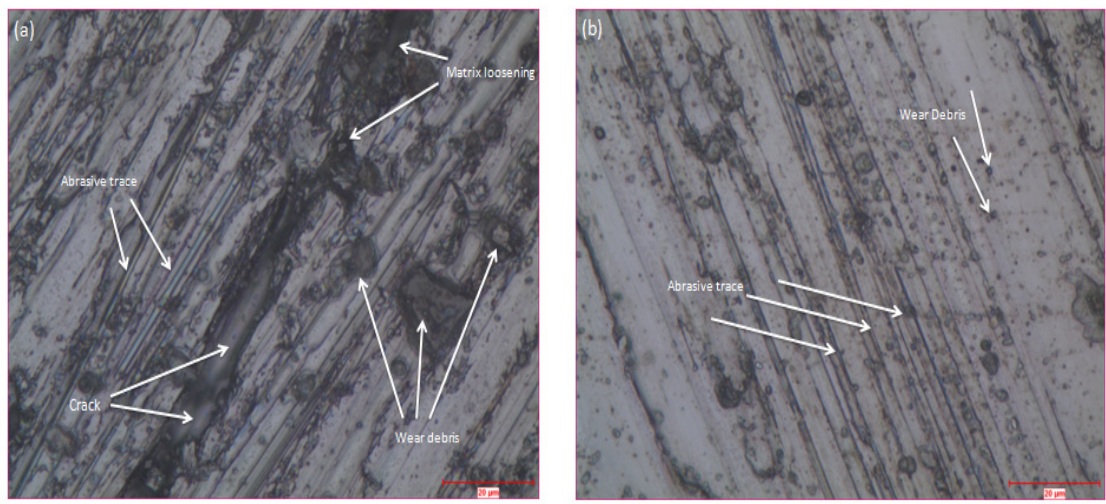

Figure 5: (a) Worn surfaces of the Astaloy $85 \mathrm{Mo}+0.5 \% \mathrm{C}$ camshaft spur gear;

(b) gas carburized Astaloy $85 \mathrm{Mo}+0.5 \% \mathrm{C}$ camshaft spur gear. 


\section{Conclusions}

The effect of gas carburizing on the microstructure, density, hardness and wear properties of Astaloy $85 \mathrm{Mo}+0.5 \%$ graphite were investigated. The following conclusions have been reached:

1-) It can be seen that the microstructure of sintered Astaloy $85 \mathrm{Mo}+0.5 \% \mathrm{C}$ is ferritic and in gas carburized Astaloy $85 \mathrm{Mo}+0.5 \% \mathrm{C}$ microstructure is plate martensite that has high carbon content at the surface and in the core which is lath martensite with low carbon content.

2-) For gas carburized Astaloy $85 \mathrm{Mo}+0.5 \% \mathrm{C}$, wear rate was very small, and wear rate was observed mainly as abrasive traces and wear debris. Gas carburized spur gear exhibit lower wear rate than the un-heat treated spur gear due to increased hardness and its microstructure. The weight loss of gears under $60 \mathrm{~N}$ applied load was measured as $0.1433 \mathrm{~mm}^{3} / \mathrm{m} \mathrm{g}$ for gas carburized Astaloy $85 \mathrm{Mo}+0.5 \% \mathrm{C}$ and that is 4.374 times greater than that of gears without gas carburized gears.

3-) Gas carburized Astaloy $85 \mathrm{Mo}+0.5 \% \mathrm{C}$ is suitable for gear production in automotive applications.

\section{References}

[1] Hausner H.H., Mal K. "Handbook of powder metallurgy". New York: Chemical Publications; 1982.

[2] Y. Takeya, T. Hayasaka, M. Suzuki, "Surface Rolling of Sintered Gears", SAE International Congress and Exposition, Detroit, Michigan, February 22-26, 1982, Paper No. 820234.

[3] P.K. Jones, K. Buckley-Golder, H. David, R. Lawcock, D. Sarafinchan, R. Shivanath, L. Yao, "Fatigue Properties of Advanced High Density Powder Metal Alloy Steels for High Performance Powertrain Applications", PM World Congress and Exhibition, Vol. 3., October 18-22, 1998, Grenada, Spain, 155-166.

[4] S. Bengtsson, L. Fordén, S. Dizdar and P. Johansson "Surface Densified P/M Transmission Gear" PM01-25: Paper presented at 2001 International Conference on "Power Transmission Components. Advances in High Performance Powder Metallurgy Applications" Ypsilanti, Michigan, USA, October 16-17, 2001.

[5] N.N. "Powder metal gears up for a hard-nosed approach", Metal Powder Report, No. 6, June, 2003, 24-30.

[6] Rajan, T.V., Sharma, C.P. and Ashok Sharma, Heat Treatment Principles and Techniques, Prentice Hall, New Delhi, 1994. R/e. 
[7] Antón N, Delgado J.L., Velasco F, Torralba J.M. "Influence of alloying element additions on tribological behavior of sintered steels with high content in Manganese-Nickel". J Mater Proc 2003; 143-144: 475-80.

[8] Khorsand H., Habibi S.M., Yoozbashizadea H., Janghorban K., Reihani S.M.S., Rahmani Seraji H. et al. "The role of heat treatment on wear behavior of powder metallurgy low alloy steels". Mater Design 2002; 23: $667-70$.

[9] Straffelini G., Molinari A. "Effect of hardness on rolling-sliding damage mechanisms in PM alloys". Powder Metal J 2001; 344-50.

[10] Wang J., Danninger H. "Dry sliding wear behavior of Molybdenum alloyed sintered steels". Wear 1998; 222: 49-56.

[11] Simchi A., Yoozbashizedeh H., Khorsand H., Ashtari M., Mordakhani D., Davami P. "The role of microstructure on wear and fatigue behavior of sintered steels". Proceedings of the PM Auto 99 International Conference Isfahan, Iran 1999.

[12] Simchi A., Danninger H. "Effect of porosity on delamination wear of sintered plain iron". Powder Metall J 2004; 44: 73-80.

[13] Lorella Ceschini, Giuseppe Palombarini, Giuliano Sambogna, Donato Firrao, Giorgio Scavino, Graziano Ubertalli. "Friction and wear behavior of sintered steels submitted to sliding and abrasion tests". Tribology International 2005, 39, (2006) 748-755. 